\title{
Editorial
}

\section{Turismo Insular Africano: múltiplos olhares sobre a experiência Cabo-verdiana}

\author{
Edgar Bernardo* \\ Universidade de Trás-os-Montes e Alto Douro (Portugal)
}

Há pouco mais de 500 anos os primeiros serviços regulares e profissionais associados ao que chamamos hoje de turismo começavam a surgir no continente europeu. Estes seriam cimentados e expandidos nos séculos XVII e XVIII com as novas posses territoriais coloniais de vários países europeus. Por terra ou por mar, o número de pessoas com capacidade de desfrutar de viagens pela Europa e pelo resto do mundo aumentava ainda que a grande maioria pertencesse a famílias aristocratas abastadas. Com a Revolução Industrial e os seus avanços tecnológicos, melhoria das vias de comunicação, invenções, a burguesia emergente expande, melhora e diversifica a atividade. Do Expresso do Oriente aos cruzeiros intercontinentais só as duas grandes guerras mundiais travariam o seu crescimento ainda que momentaneamente.

Os acrescidos avanços e melhorias tecnológicas e sociais, e a rápida recuperação económica e industrial da Europa Ocidental permitiu um crescimento na atividade turística que superaria todas as expetativas. Com o desenvolvimento dos transportes, e todo um conjunto de alterações socioeconómicas, como por exemplo a implementação do Estado-Providência, e ainda com a independência de um vasto conjunto de países no final do conflito, as portas abriam-se para que o turismo se tornasse uma atividade apetecível, viável e confortável.

Atualmente, já ultrapassados os mil milhões de turistas mundiais, projeta-se que no ano de 2030 se atinjam 1,9 mil milhões. Este movimento de pessoas tem feito fluir receitas que continuam a favorecer as economias mais desenvolvidas, sendo a Europa ainda o principal gerador de turistas a nível mundial. Apesar deste desenvolvimento acentuado, a região menos visitada continua a ser o Médio Oriente, logo seguida de África, praticamente a par da Ásia e Pacífico. Tanto em África como no Médio Oriente, o reduzido e tardio crescimento do número de turistas é justificável pelo clima de insegurança política e social que estas regiões ainda vivem, apesar de desde 2000 se constatar um crescimento tanto no número de turistas, como na emissão de turistas.

No que se refere ao crescimento do turismo em África, a UNWTO (2017) conclui que este continente recebe apenas 5\% dos turistas mundiais (aproximadamente 63 milhões de turistas), recolhendo meros $3 \%$ das receitas globais. Na região classificada de África subsariana, países como Quénia, Costa do Marfim, Maurícias e Zimbabué continuam a liderar, emergindo em acelerado crescimento destinos como Seicheles e Cabo Verde. Apesar de crescer num ritmo mais lento, a atividade no continente africano demonstra que investidores e governos estão particularmente atentos aos seus benefícios tanto à escala macro (nacional) como micro (local). O turismo representa aumento de consumo por parte de estrangeiros nos países recetores, o que significa mais dinheiro em impostos a recolher, mas também uma melhoria da qualidade de vida, maior distribuição de riqueza e criação de empregos.

$\mathrm{O}$ turismo exige uma variedade de serviços, infraestruturas e investimentos que permitam gerar e aproveitar oportunidades, gerir crescimento e, sobretudo, a capacidade de adaptação às mudanças de modo a garantir que não afeta os objetivos estabelecidos para o crescimento ao nível local e nacional. Mas turismo é muito mais que uma atividade económica, pois implica interações entre pessoas (Tribe, 1997). Turismo é a soma das ideias e ideologias do que é ser turista (Leiper, 1990) e, ao envolver a

\footnotetext{
E-mail: edgaracb@utad.pt
} 
articulação de serviços e pessoas, tem uma dimensão social valiosa a considerar (Goeldner et al., 2002) que implica práticas e representações sociais (Lohmann e Neto, 2012).

Em outras palavras, investigar turismo implica compreender, e compreender turismo exige múltiplos olhares, perspetivas e pontos de partida. Por este motivo são múltiplas as ciências, em particular as sociais que o abordam. É um campo com uma pluralidade desafios e oportunidades (Smith, 1995). Da Geografia, à Antropologia, Economia, Sociologia, entre outras, cada área de conhecimento pode acrescer à sua compreensão. Este conhecimento é da maior pertinência tanto pela sua vertente teórico-académica como pela sua vertente técnico-institucional.

O quadro de conhecimento associado à implementação política é da maior importância para muitos governos de países em desenvolvimento para quem o mercado turístico é entendido como a única saída para as precariedades e debilidades das suas economias. Estes países, pela sua profunda dependência face ao investimento externo em infraestruturas, à capacidade e conhecimento de técnicos e especialistas estrangeiros para garantir um serviço adequado e exigido pelos turistas internacionais, podem acabar por aprofundar o desvio de dividendos dos seus países para os países mais desenvolvidos de onde oriunda a maioria dos turistas e dos provedores de serviços diretos e indiretos associados ao turismo internacional (Mowforth e Munt, 2003).

Tais consequências levam à associação do turismo, em particular o turismo internacional massificado, como uma forma de neocolonização que recorre aos imaginários romantizados de lugares distantes, selvagens e paradisíacos, e dá continuidade à exploração de recursos naturais e culturais de países fragilizados. Outros vêm nesta aposta um passo seguinte natural do capitalismo tardio que subsiste do mercado global e interdependente.

Sem dúvida que na balança dos benefícios as fugas de mais valias subsistem como principal entrave ao desenvolvimento, mas estas podem ser aprofundadas, se o setor público esconder ou mascarar os impactos negativos do turismo de forma a garantir o interesse de mais investidores e o crescimento do turismo (Tosun, 2002). Brida et al. (2011) defende que o turismo sustentável exige maior entrosamento entre os setores público e privado, e uma aposta do setor público na educação e formação dos intervenientes, para que as comunidades possam participar na resolução de problemas comuns e na gestão turística.

Um processo constante de modernização por uma modernidade globalizadora baseada num desenvolvimento "em vias de" e que, mesmo reconhecendo a sua ambiguidade (Friedman, 1996), se pretende sustentável. O turismo é apresentado como a estratégia modernizadora ideal apesar dos elevados riscos associados ao fracasso e até mesmo ao sucesso da sua implementação. Riscos que obrigam à consideração do papel dos governos, e dos elementos da governança turística. Esta postura messiânica que sobrepõe metas económicas aos seus impactos pode condenar e aprofundar a condição de dependência destes mesmos países e suas comunidades.

No caso particular do continente africano, importa implementar mecanismos de transparência e responsabilização dos investidores e exigir o desenvolvimento de recursos humanos locais e o consumo de produtos endógenos, permitindo um aumento da retenção de dividendos ao nível local e nacional. Os governos africanos, por seu turno, devem olhar para o turismo e o seu futuro recorrendo às suas próprias experiências e lições apreendidas, adaptando a atividade às suas condições, recursos e objetivos específicos, entre eles procurar políticas que potenciem os benefícios do turismo não só para o setor económico e para as elites (Dieke, 2000).

Este número especial parte do reconhecimento da necessidade de uma maior transferência de conhecimento científico para a vertente pública e propõe apresentar diferentes abordagens, científicas e metodológicas sobre o turismo num contexto que tem desfrutado há algumas décadas de um rápido crescimento económico assente na atividade turística. Porquê escolher um destino insular? Pela beleza natural das ilhas e o seu património interligado às suas civilizações nativas e à ocupação colonialista, estas estão envoltas de uma mística que continua a captar o imaginário de turistas por todo mundo (Choudhary, 2010). Como infere Baldacchino (2015), são lugares que insulam simbolicamente os seus visitantes, são escapatórias do quotidiano agrupadas a associações idílicas.

A escolha de Cabo Verde como estudo de caso prende-se com o facto de se enquadrar neste perfil de país africano em desenvolvimento cuja economia se centra na atividade turística, mas não só. A sua proximidade geográfica, cultural e o desenvolvimento turístico acelerado tornam este arquipélago um laboratório único, sobretudo se considerarmos os diferentes ritmos e propostas turísticas que as suas várias ilhas apresentam ou pretendem criar.

Esta variedade está espelhada nos vários artigos compilados que relatam diferentes perspetivas e cronologias sobre o fenómeno turístico cabo-verdiano, seus impactos e dinâmicas. Este número especial inicia-se com o artigo de Rovisco que analisa artigos de promoção e informação turística do semanário 
'O Arquipélago' entre 1962 e 1974, revelando a forma como o arquipélago foi descrito e promovido no período colonial português.

Seguidamente, Quintana e Morales apresentam-nos uma descrição geográfica e histórica do percurso de Cabo Verde e o desenvolvimento do fenómeno turístico no arquipélago refletindo sobre as potencialidades que o turismo não massificado pode trazer para o país.O artigo de Fernandes, Ribeiro e Lima analisa a forma como o destino cabo-verdiano é promovido recorrendo a entrevistas aplicadas a turistas portugueses retirando ilações sobre a sua estratégia de promoção nos mercados externos. Promoção essa que Marcelino e Gonzaléz abordam desde a criação da marca nacional "Cabo Verde um país, 10 destinos" e como esta condiciona a imagem, o património e o próprio desenvolvimento das várias ilhas usando o caso de Santiago, e da Cidade Velha, como estudo de caso.

Morais sugere uma perspetiva sobre os impactos do turismo desde as organizações do terceiro setor, na ilha da Boa Vista, mostrando-nos as carências, mas também o potencial que o turismo pode ter para a implementação de práticas socialmente empreendedoras. Um contributo pertinente se considerarmos os resultados do trabalho de Bernardo e Jorge sobre as perceções sobre os impactos do turismo nesta ilha e a sua relação com as dinâmicas de governança turística atualmente existentes e para o futuro.

Popinsky transporta-nos para a ilha do Fogo onde caracteriza a atividade turística atual como o resultado da história, dos meios de produção rurais e das dinâmicas familiares da comunidade de Chãs das Caldeiras, que se distingue de outros destinos nacionais. Igualmente distintivo é o Carnaval de Mindelo sobre o qual Daun e Lorena trabalhou em torno das disputas económicas e simbólicas que acarreta mostrando como um evento turístico promovido como cartão de visita para o mundo, reflete dinâmicas identitárias e políticas que merecem uma abordagem mais atenta dadas as suas implicações.

No âmbito do turismo cultural, Sarmento devolve-nos a Santiago onde propõe que o artesanato pode ter um papel central na promoção da cultura cabo-verdiana, bem como contribuir ativamente para a sua preservação e valorização e, simultaneamente, para o rendimento das comunidades locais.

Este número é encerrado por duas resenhas de livros já publicados. Rodrigues e Rodrigues resumem, "Island Tourism" de V. Choudhary e "Archipelago Tourism: policies and practices" de G. Baldacchino, duas obras que nos partilham diversos estudos sobre o turismo e os seus impactos em territórios insulares um pouco por todo o mundo. Obras que são fundamentais para um conhecimento essencial das características e dinâmicas particulares que estes lugares partilham.

Praticamente após um ano da apresentação pública do Plano Estratégico de Desenvolvimento Sustentável de Cabo Verde, 2017-2021, este número surge num período que politicamente se apresenta como de reposicionamento dos objetivos e das práticas da gestão e estratégia política para o turismo de Cabo Verde. Um virar de página que reconhece os fracassos e mais valias dos modelos anteriores, muitos deles espelhados nos vários artigos aqui reunidos, e que procura reescrever a história, a identidade e o futuro do arquipélago. É também para a posterioridade que este volume procura concentrar estes trabalhos. Procuramos que políticos, investigadores, académicos, membros de comunidades locais de hoje, como de amanhã, consigam aceder a estes contributos e deles retirar o proveito que necessitem.

Seja para uma melhor compreensão do turismo cabo-verdiano, africano, insular, pós-colonial, etc., ou das dinâmicas identitárias, políticas e económicas que são transversais e comuns a outros fenómenos sociais, pretendemos acrescentar ao conhecimento adquirido, partilhando-o.

\section{Bibliografia}

Brida, Juan, Pablo Monterubbianesi, Sandra Zapata-Aguierre

2011. "Impactos del Turismo sobre el Crecimiento económico y el desarrollo. El caso de los principales destinos turísticos de Colombia". Pasos - Revista de Turismo y Património Cultural, 9(2): 291-303. Dieke, $\mathrm{P}$.

2000. "Developing Tourism in Africa: Issues for Policy Consideration", DPMN Bulletin, 7(1): 25-31. Friedman, John

1996. Empowerment - Uma política de desenvolvimento alternativo. Oeiras: Editora Celta.

Goeldner, Charles, Brent Richie, Robert McIntosh

2002. Turismo Princípios, Prática e Filosifia. $8^{\text {a }}$ Ed. Porto Alegre: Bookman.

Leiper, Neil

2000. "An Emerging Discipline", Annals of Tourism Research, 27(3): 805-809.

Lohmann, Guilherme, Panosso Netto

2012. Teoria do Turismo - Conceitos, Modelos e Sistemas, Editora ALEPH, São Paulo. 
Mowforth, Martin, Ian Munt

2003. Tourism and Sustainability, $2^{\circ}$ edition. London: Routledge.

Tribe, John

1997. "The Indiscipline of Tourism", Annals of Tourism Research, 24(3): 638-657.

Tosun, Cevat

2002. "Host Perceptions of Impacts, a Comparative Tourism Study", Annals of Tourism Research, 29(1): 231-253.

UNWTO

2018. UNWTO Tourism Highlights - 2018 Edition. https://www.e-unwto.org/doi/pdf/10.18111/9789284419876 